\title{
3D Hand Measuring with a Mobile Scanning System
}

\author{
Anke KLEPSER ${ }^{* a}$, Michel BABIN ${ }^{b}$, Christine LOERCHER ${ }^{a}$, Elfriede KIRCHDOERFER, \\ Jan BERINGER ${ }^{\mathrm{a}}$, Andreas SCHMIDT ${ }^{\mathrm{a}}$ \\ ${ }^{a}$ Hohenstein Institut fuer Textilinnovation gGmbH, Boennigheim, Germany; \\ ${ }^{\mathrm{b}}$ TechMed 3D Inc., St. Nicolas, Canada
}

\begin{abstract}
Gloves are an important part of personal protection equipment (PPE). Function in terms of adequate thermo physiological comfort and protection is only given with perfect fit. Little is known about hand dimensions in Germany and other countries. Currently available measurement tables do not contain all relevant information necessary to design gloves. Hands are usually measured with a tape measure. Glove development is very traditional and mostly based on empirical data. 3D-scanning-technology would provide an innovative approach for the optimization of gloves in consideration of fit, functionality and design. 3D scanning systems for the whole body, however, are not accurate enough to achieve required detailed information for collecting hand data. They provide not enough data points and critical gaps within the point clouds. Therefore, to collect three dimensional hand data specific scanning systems are required.

The aim of a pilot study at the Hohenstein Institute was to develop a feasible acquisition setting as a basis for a hand sizing project. For data collection the Creaform Ergo Handyscan and TechMed MSoft measurement software were used. The system fulfils requirements about flexibility, data density and accuracy for the aimed purpose.

A preliminary test showed that the existing positioning point world (Maid) did not lead to a natural forearm positioning. As a result, semi-automatic measurement software was not able to detect precise data. Thus, acquisition setting was modified and economized. 200 men's hands were scanned to verify acquisitioning process and data quality. 53 hand measurements were taken. A 3D virtual model representing particular glove size was generated on the basis of these results. In another part of the project the usage of the scanning system to extract information about the fit and comfort of gloves by comparing the 3D data of the hand with and without gloves was tested. The results provide a very accurate and objective determination of fit and comfort.

As a further step, a comprehensive research project is needed to validate these findings, and to revise the accuracy of existing measurement tables. Then, 3D virtual and physical hand models representing each glove size can be developed.
\end{abstract}

Keywords: 3D scanning, 3D shape analysis, hand, gloves, anthropometric studies, anthropometrical measurements, virtual body models

\section{Introduction}

Gloves are an important part of personal protection equipment (PPE). Handling hot or cold materials respectively sharp-edged construction parts requires insulation or cover. The advantages for workers are indisputable furthermore employers take economic benefit of preventive measures [1]. In addition, the percentage of women in traditional men's jobs is increasing [2]. Therefore, protective gloves are more and more used.

Function in terms of adequate thermo physiological comfort and protection is only given with perfect fit. Little is known about hand sizes and hand geometry.

For the clothing sector ISO 8559:1989 [3], DIN EN 13402-1 [4] and ISO 3635-1981 [5] define the location and taking of body dimensions. According to these standards hand girth (circumference) is "the maximum girth over the knuckles (metacarpals) of the open right hand, with the fingers together and the thumb excluded" and hand length is "the distance, measured with the lower arm in line with the open hand, with the fingers together and the thumb extended, between the tip of the middle finger and the first crease at the base of the right hand" [3] (see Fig. 1).

*a.klepser@hohenstein.de; +49- 7143-271-325; www.hohenstein.de 


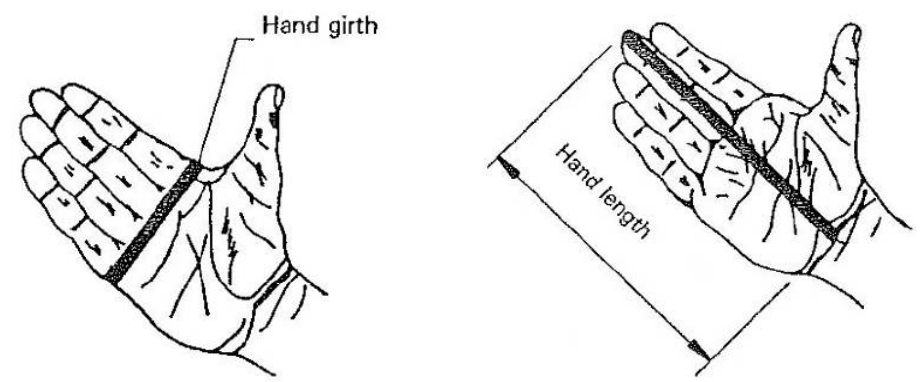

Fig. 1. Definition of location and taking of hand dimensions. [3]

In DIN EN 13402-2 [6] hand girth is defined to be the primary measure for gloves. A primary measure is a measurement that is necessary to assign the appropriate garment. DIN EN 13402-3 [7] provides hand girth and related scope all in centimeters (see Table 1).

Table 1. Standard hand girth [cm].

\begin{tabular}{|l|c|c|c|c|c|c|c|c|}
\hline $\begin{array}{l}\text { Hand } \\
\text { girth }\end{array}$ & $\mathbf{1 4}$ & $\mathbf{1 4 , 5}$ & $\mathbf{1 5}$ & $\mathbf{1 5 , 5}$ & $\mathbf{1 6}$ & $\mathbf{1 7}$ & $\mathbf{1 8}$ & $\begin{array}{c}\text { Skip } \\
\text { value }\end{array}$ \\
\hline Area & $13,8-14,3$ & $14,3-14,8$ & $14,8-15,3$ & $15,3-15,8$ & $15,8-16,5$ & $16,5-17,5$ & $17,5-18,5$ & 0,5 and 1 \\
\hline
\end{tabular}

\begin{tabular}{|l|c|c|c|c|c|c|c|c|}
\hline $\begin{array}{l}\text { Hand } \\
\text { girth }\end{array}$ & $\mathbf{1 9}$ & $\mathbf{2 0 , 5}$ & $\mathbf{2 2}$ & $\mathbf{2 3 , 5}$ & $\mathbf{2 5}$ & $\mathbf{2 6 , 5}$ & $\mathbf{2 8}$ & $\begin{array}{c}\text { Skip } \\
\text { value }\end{array}$ \\
\hline Area & $18,5-19,5$ & $19,5-21,3$ & $21,3-22,8$ & $22,8-24,3$ & $24,3-25,8$ & $25,8-27,3$ & $27,3-28,8$ & 1,5 \\
\hline
\end{tabular}

Manufacturers of protective glove must take into account guidelines like DIN EN 420 [8] where glove size is defined according to hand sizes. Hand size is a code based on hand girth and it stands for hand girth in Inch. The two systems are not really matching currently.

Table 2. Hand sizes according to DIN EN 420.

\begin{tabular}{|c|c|c|c|c|}
\hline $\begin{array}{c}\text { Hand size } \\
\text { [inches] }\end{array}$ & Hand girth [mm] & Length [mm] & Glove size & $\begin{array}{c}\text { Minimum glove length } \\
\text { [mm] }\end{array}$ \\
\hline 6 & 152 & 160 & 6 & 220 \\
\hline 7 & 178 & 171 & 7 & 230 \\
\hline 8 & 203 & 182 & 8 & 240 \\
\hline 9 & 229 & 192 & 9 & 250 \\
\hline 10 & 254 & 204 & 10 & 260 \\
\hline 11 & 279 & 215 & 11 & 270 \\
\hline
\end{tabular}

In Table 2 hand girth is correlated with hand length and it is shown which glove size should fit to which hand size. Furthermore, it provides a minimum glove length for each size. Glove length is measured with a scale vertically held where minimal length from distance middle finger tip to end of cuff is recorded. The ergonomic standard DIN 33402-2 [9] provides numerous and detailed information about hand dimensions. As common in this sector data is clustered into percentile and not correlated to glove sizes. Therefore, it does not contain all relevant information necessary to design gloves. 1988 US Army hand anthropometric survey report provided comprehensive statistical information [10]. However, test person were measured by hand and military personnel can not be considered as average. This makes it difficult to work with those results.

Glove development is very traditional craftsmanship and mostly based on empirical data. And yet until fairly recently even in research projects hands were usually measured with a tape measure [11]. 3D-scanning-technology would provide an innovative approach for the optimization of gloves in consideration of fit, functionality and design. Developments in garment industry and previous research projects have shown how 3D scanning information can provide fit relevant information for the garment design (such as Kirchdörfer 2011 [12]; Krzywinski et.al 2011 [13]). Virtual average 3D models, cross-sections, curves and surfaces can be generated. They can be a valuable basis for detailed analyses and 3D glove construction.

However, already gathered 3D body data can not be used for glove design. 3D scanning systems for the whole body are not accurate enough to achieve required detailed information for collecting hand data. They provide to less data points and critical gaps within the point clouds. Therefore, to collect three dimensional hand data specific scanning systems are required. 


\section{Method}

The aim of a pilot study at the Hohenstein Institute was to develop a feasible acquisition setting as a basis for a large-scale hand size project. For data collection the Creaform Ergo Handyscan and TechMed MSoft measurement software were used.

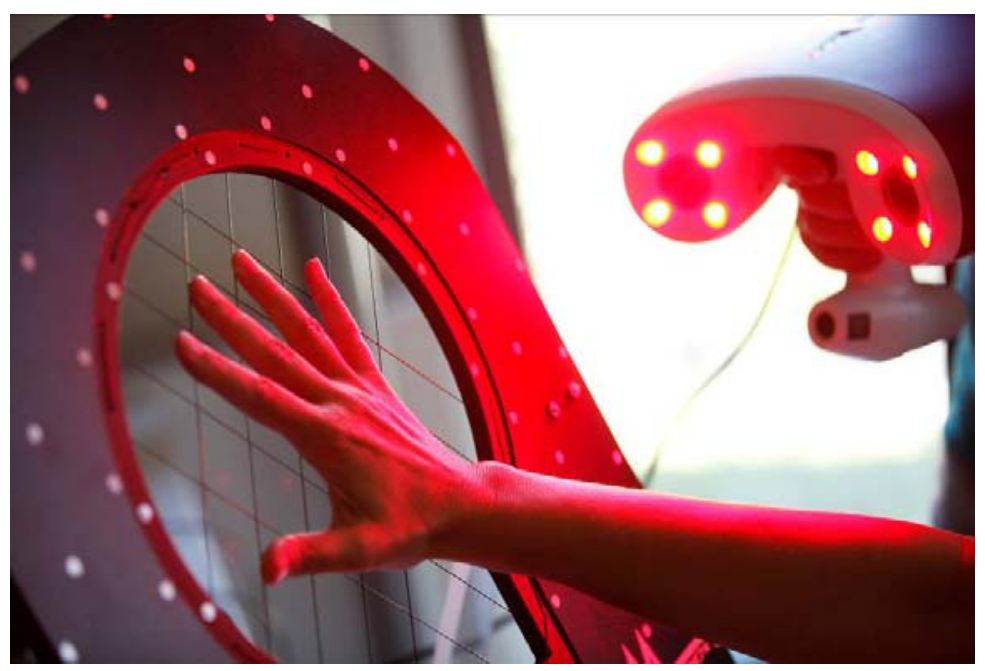

Fig. 2. Creaform Ergo Handyscan acquiring hand data.

A preliminary test showed that the existing positioning point world (Maid) did not lead to a natural forearm positioning. As a result, semi-automatic measurement software could not detect precise data. Thus, acquisition setting was modified and economized. The requirements to the modification were stable output data, short acquisition time, comfortable and natural body posture of the subject, comfortable body posture and movement of scanning staff.

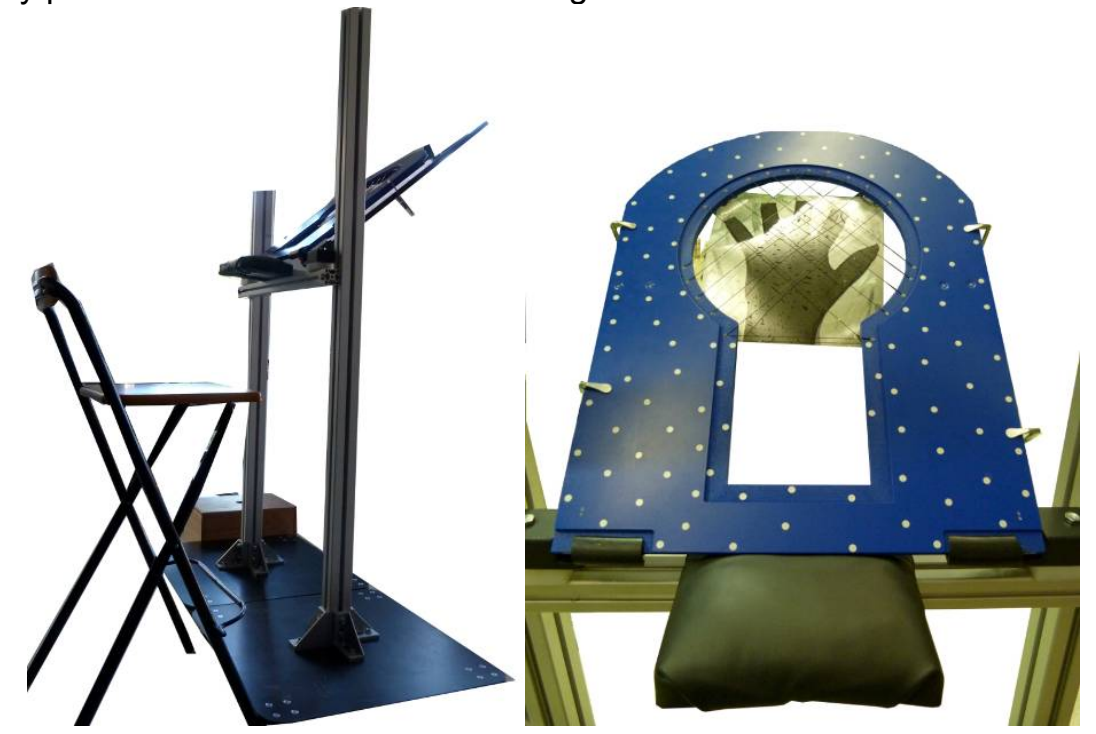

Fig. 3. Test set up (left); Armrest, Maid with positioning points and film (right).

A suitable solution to fulfill the requirements is shown in figure 3. A subject is sitting on a bar stool one arm on an armrest to minimize shaking. Armrest and connected Maid can be adjusted in height. The arm is held as relaxed as possible and the angle at the elbow is approximately $45^{\circ}$. The aim is optimum 3D data quality for the following semi-automatic measurement. Arm, hand and fingers have to be acquired in a defined position to allow measuring without post processing the 3D files. Therefore an additional help was provided, a film with a sketched hand was attached to the board with magnets. The foil gave orientation about the necessary amount of spreading the fingers. For acquisition the foil can be removed. The raised seating position offers a comfortable working position for the scanning staff. To acquire fingertips and gaps between fingers a small ladder can be used.

It was observed that fragmentary data caused by sweat, shiny fingernails and hair. Baby powder was used to reduce most of those effects. However, missing data due to hair was repaired in the automatic post processing by MSoft. 48 hand measurements were taken (see Table 3 ). 
Table 3. Semi-automatic measurements acquired by MSoft.

\begin{tabular}{|c|c|}
\hline Hand Circumferences & Hand Lengths \\
\hline Arm at Wrist $-100 \mathrm{~mm}$ & 1st Metacarpal \\
\hline Arm at Wrist $-50 \mathrm{~mm}$ & 2nd Metacarpal \\
\hline Wrist & 3rd Metacarpal \\
\hline 1st and 5th Meta & 4th Metacarpal \\
\hline 2nd and 5th Meta & 5th Metacarpal \\
\hline Thumb Metacarpal & 1st Proximal Phalange \\
\hline Thumb Proximal & 2nd Proximal Phalange \\
\hline Thumb Distal & 3rd Proximal Phalange \\
\hline Index Metacarpal & 4th Proximal Phalange \\
\hline Index Proximal & 5th Proximal Phalange \\
\hline Index Intermediate & 2nd Intermediate Phalange \\
\hline Index Distal & 3rd Intermediate Phalange \\
\hline Middle Finger Metacarpal & 4th Intermediate Phalange \\
\hline Middle Finger Proximal & 5th Intermediate Phalange \\
\hline Middle Finger Intermediate & 1st Distal Phalange \\
\hline Middle Finger Distal & 2nd Distal Phalange \\
\hline Ring Finger Metacarpal & 3rd Distal Phalange \\
\hline Ring Finger Proximal & 4th Distal Phalange \\
\hline Ring Finger Intermediate & 5th Distal Phalange \\
\hline Ring Finger Distal & Thumb \\
\hline Pinky Metacarpal & Index \\
\hline Pinky Proximal & Middle Finger \\
\hline Pinky Intermediate & Ring Finger \\
\hline Pinky Distal & Pinky \\
\hline
\end{tabular}

The data was transferred automatically into an Excel-chart. This eliminates copy/paste errors. The advantage of digital measurement is that it is repeatable which allowes a quality control of the collected data. Mistakes could be identified and fixed. Microsoft Office Excel 2003 was used for statistical analysis and evaluations. A first draft of measurement table was developed. For generating virtual 3D hand models Geomagic studio 2012 was used. 87 scans with matching hand girth were aligned and virtually averaged. Test person with hand size 10 donned gloves with the appropriate size. Gloves and hands were scanned. 3D analyses with Geomagic studio 2012 were performed.

\section{Results}

200 men's hands (100 probands, Age 16-75) were scanned to verify acquisitioning process and data quality. Eight statistical outliers have been deducted. Test person were all living in German federal state Baden-Württemberg. Range of body height was $162-197 \mathrm{~cm}$ and mean $180.8 \mathrm{~cm}$ which is 1.06 $\mathrm{cm}$ taller than the findings in SizeGERMANY the recent body sizing survey realized 2007-2009 [14]. $84 \%$ were right handed, $9 \%$ left handed and $7 \%$ use right and left hand equally. 


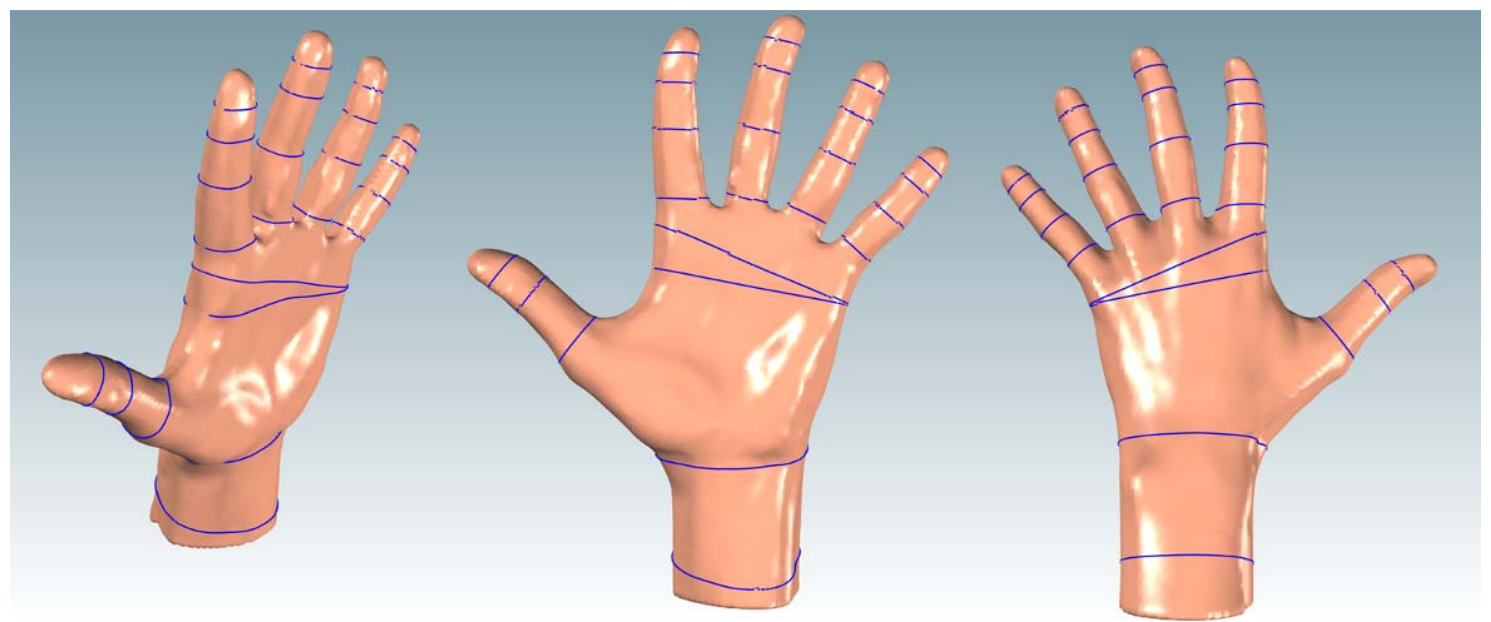

Fig. 4. Hand measures positioned on individual hand.

Due to the semi-automatic measurement hand position it had to be with the fingers spread (see Figure 4). However, the defined hand position is not as prescribed in DIN EN 420. Therefore, differences in hand girth due to hand position had to be analyzed. 7 test person's hands were measured in MSoft position (fingers spread) and DIN EN position. Differences between 1.9 to $4.9 \mathrm{~mm}$ were found. On average this is $1.7 \%$ of hand girth. This factor has to be validated in an additional survey. For further analysis the factor was deducted from hand girth. The following findings are based on this new calculated hand girth.

The average hand girth was $216.4 \mathrm{~mm}$ which is glove size 8.5 and average hand length was 197.26 $\mathrm{mm}$ which is glove size $9.5 .29 .8 \%$ of the test person had different hand sizes in left and right hand. Only $11.2 \%$ of the test person's hands fitted into glove sizes in girth and length according to DIN EN 420 (see Figure 5). In $81.9 \%$ size due to hand length was bigger than size due to hand girth, in some cases up to 2.5 size numbers.

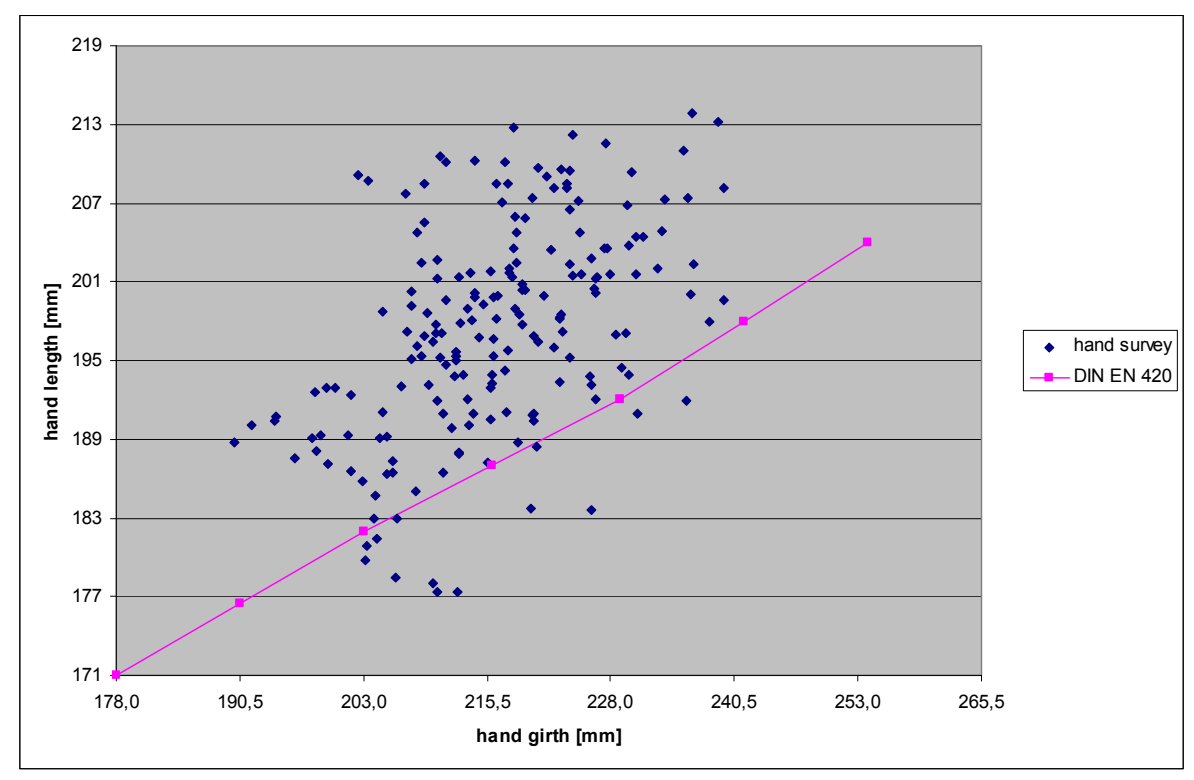

Fig. 5. Hand girth/length compared to DIN EN 420 hand sizes.

Hand length is calculated from two measurement sections: 1. length of third metacarpal - wrist circumference to metacarpophalangeal joint (where the finger meets the palm) and 2. middle finger length - metacarpophalangeal joint to finger tip. Ratio of the proportions was in mean $58.4 \%$ metacarpal to $41.6 \%$ finger length. This proportion remained constant thru all sizes with only a minor deviation. Data analysis revealed significant correlation of body height with hand length $(r=.55, p$ $<.001)$, of body height with hand girth $(r=.22, p<.01)$ and of hand girth with hand length $(r=.50$, $p<.001)$.

A 3D virtual model representing glove size 8.5 was generated on the basis of these results (see Figure $6)$. 


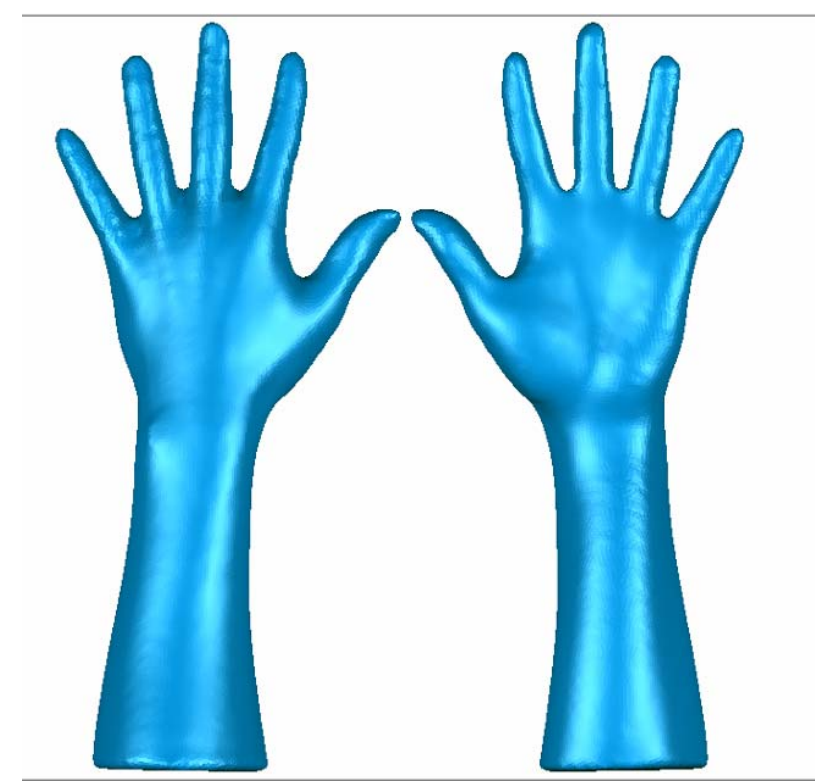

Fig. 6. 3D virtual model hand size 8.5.

In another part of the project the usage of the scanning system to extract information about the fit and comfort of gloves by comparing the 3D data of the hand with and without gloves was evaluated.

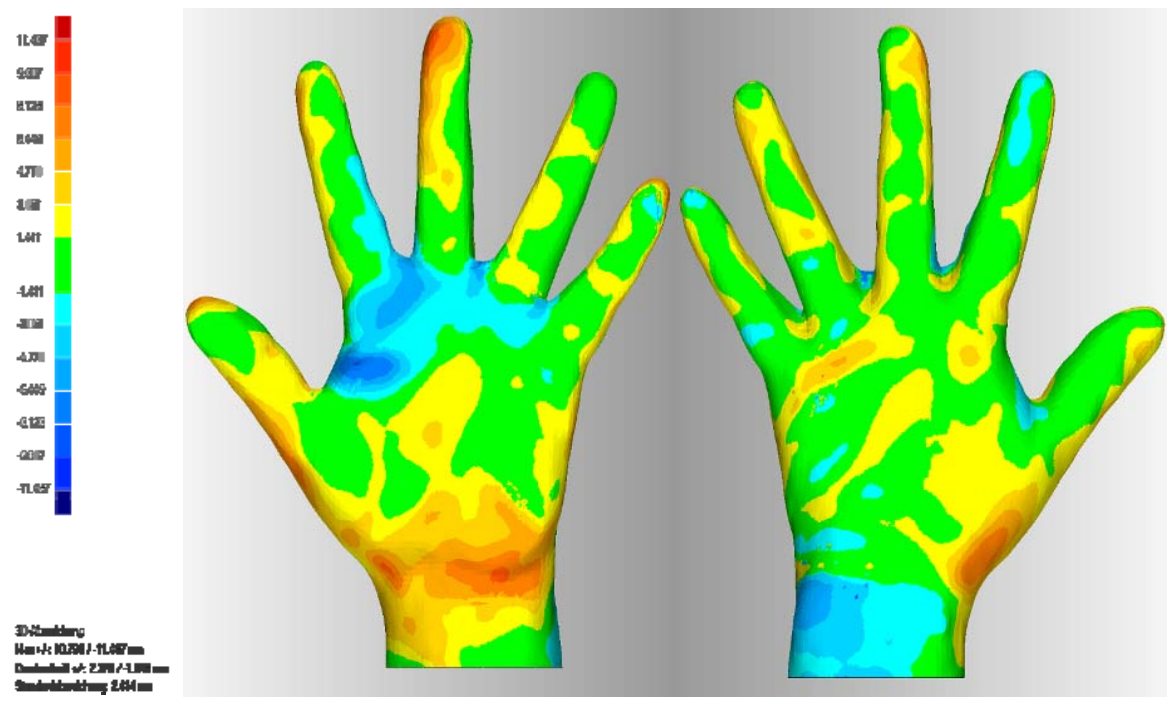

Fig.7. 3D analysis of a glove lining.

Figure 7 shows perfect fit in green color, compressing parts in light blue and blue color and distant sections in yellow, orange and red.

\section{Conclusions}

The system fulfils requirements about flexibility, data density and accuracy for the aimed application. Scanner and set up is portable and relevant groups can be acquired at different places. Time consuming journeys for test person can be reduced. Acquisition is fast and additionally entertaining for subjects due to real time video picture on the computer monitor. Detailed measurements can be a base for profound investigation of hand dimension correlation. Findings showed that DIN EN 420 hand measurement chart should be revised with regard to market coverage. 3D virtual models give comprehensive geometrically information for further analysis. The results of the $3 \mathrm{D}$ analysis provide a very accurate and objective determination of fit and comfort. Furthermore, it can be used for examination thermo physiological comfort by describing insulating air layers and surface areas.

Differences in hand girth due to differing hand position have to be investigated in an additional study. As a further step, a comprehensive research project is needed to replicate these findings, and to revise the accuracy of existing measurement tables. Then, 3D virtual and physical hand models representing each glove size can be developed. 


\section{References}

1. DGUV "Erfolgsfaktor Arbeitsschutz: Studie belegt betriebswirtschaftlichen Nutzen von Prävention" (accessed 2012): http://dguv.de/inhalt/presse/2012/Q1/return-on-prevention/index.jsp.

2. (2012): "Die weibliche Seite des Arbeitsschutzes - Frauen erobern Männerdomänen, der Bedarf an PSA steigt", Personel Protection \& Fashion, 2, 25-27.

3. ISO 8559:1989 (E): "Garment construction and anthropometric surveys - Body dimensions".

4. DIN EN 13402-1:2001: "Größenbezeichnung von Bekleidung Teil1: Begriffe und Verfahren für die Messung am Körper".

5. ISO 3635-1981 (E): "Size designation of clothes - Definitions and body measurement proceure".

6. DIN EN 13402-2:2002: "Größenbezeichnung von Bekleidung Teil 2: Größenbezeichnung von Bekleidung".

7. DIN EN 13402-3:2004: "Größenbezeichnung von Bekleidung Teil 3: Maße und Sprungwerte".

8. DIN EN 420:2010: "Schutzhandschuhe - Allgemeine Anforderungen und Prüfverfahren".

9. DIN 33402-2:1978: "Ergonomie - Körpermaße des Menschen - Teil 2: Werte".

10. Greiner, T. M., (1991): "Hand Anthropometry Of U.S. Army Personnel", United States Army Natick Research, Develeopment And Engineering Center, Natick (USA).

11. Willms, K., Wells, R., Carnahan, H., (2009): "Glove Attributes and Their Contribution to Force Decrement and Increased Effort in Power Grip", Human Factors: The Journal of the Human Factors and Ergonomics Society, 51, 6, 797-812.

12. Kirchdörfer, E., (2011): "Entwicklung einer automatischen, körperkonformen Konstruktionssystematik für Oberbekleidung auf Basis von 3D Körper Informationen. Aif-Vorhaben Nr. 15605 N", Hohenstein Institut für Textilinnovation e.V.

13. Krzywinski, S., Hlaing, E.C., Morlock, S., Kirchdörfer, E., (2011): "Entwicklung virtueller 3DFormkörper für die untere Körperhälfte von Frauen auf Basis von 3D-Scandaten", Forschungsbericht, IGF-Forschungsvorhaben Nr. 15972 BG, Institut für Textilmaschinen und Textile Hochleistungswerkstofftechnik, Technische Universität Dresden, Hohenstein Institut für Textilinnovation $\mathrm{gGmbH}$.

14. SizeGERMANY (accessed 2012): www.sizegermany.de. 